\title{
Desidratação osmótica de fatias de mamão (Carica papaya $\mathbf{L}$.
}

\section{Osmotic dehydration of papaya slices (Carica papaya L.)}

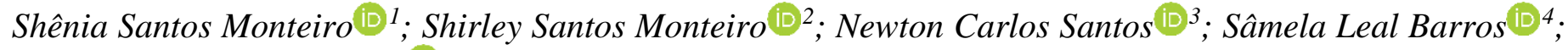 \\ Emmanuel Moreira Pereira (D5
}

${ }^{1}$ Mestranda em Engenharia Agrícola, Universidade Federal de Campina Grande, Campina Grande, shenia-monteiro@hotmail.com; ${ }^{2}$ Doutoranda em Engenharia Agrícola, Universidade Federal de Campina Grande, Campina Grande, shirley_pinto_monteiro@ hotmail.com; ${ }^{3}$ Doutorando em Engenharia Química, Universidade Federal do Rio Grande do Norte, Natal, newtonquimicoindustrial@gmail.com; ${ }^{4}$ Doutorando em Ciência e Tecnologia de Alimentos, Universidade Federal do Ceará, Fortaleza, samelaleal7@gmail.com; ${ }^{5}$ Doutor em Agronomia, Universidade Estadual Paulista Júlio de Mesquita Filho, Jaboticabal, São Paulo, emmanuel16mop@hotmail.com.

\section{A R T I G O}

Recebido: 07/01/2020

Aprovado: 17/03/2020

Palavras-chave: Carica papaya $\mathrm{L}$. Micro-ondas Secagem

\section{Key words:}

Carica papaya $\mathrm{L}$.

Microwave

Drying

\section{R E S U M O}

A aplicação de tecnologias como a desidratação osmótica, promove a redução da água do produto em curtos períodos e a melhoria de suas características sensoriais. Uma vez observada a influência das condições na eficiência do processo de desidratação osmótica de frutos, objetivou-se com esse estudo avaliar o efeito da temperatura e das concentrações de sacarose e xilitol na cinética de desidratação osmótica, e os efeitos da secagem complementar em micro-ondas nas características físicas e químicas de fatias de mamão papaia. O método de análise de superfície de resposta foi aplicado através de um planejamento fatorial rotacional completo $2^{2}$ com 4 pontos axiais e 3 repetições no ponto central, totalizando 11 experimentos para cada agente osmótico, com o qual, foi possível avaliar os efeitos da concentração do agente osmótico (sacarose ou xilitol) e da temperatura, na perda de água das fatias de mamão Verificou-se que a condição ideal para a realização do processo foi a concentração de $50{ }^{\circ} \mathrm{Brix}$ do agente osmótico na temperatura de $30^{\circ} \mathrm{C}$. As fatias submetidas a desidratação osmótica nessas condições foram secas em micro-ondas e avaliadas quanto as suas características físicas e químicas. A utilização do xilitol como agente osmótico foi mais eficiente do que a sacarose, proporcionando uma maior redução da água, influenciando significativamente na retenção do conteúdo de vitamina $\mathrm{C}$ após secagem em microondas e apresentando menor teor de água.

\section{A B S T R A C T}

The application of technologies such as osmotic dehydration, promotes the reduction of product water in short periods and the improvement of its sensory characteristics. Once the influence of conditions on the efficiency of the osmotic dehydration process of fruits was observed, the objective of this study was to evaluate the effect of temperature and sucrose and xylitol concentrations on osmotic dehydration kinetics, and the effects of complementary microwave drying. on the physical and chemical characteristics of papaya slices. The response surface analysis method was applied through a complete $2^{2}$ rotational factorial design with 4 axial points and 3 repetitions at the central point, totaling 11 experiments for each osmotic agent, with which it was possible to evaluate the effects of the agent concentration osmotic (sucrose or xylitol) and temperature, in the loss of water from the papaya slices It was found that the ideal condition for carrying out the process was the 50 ${ }^{\circ}$ Brix concentration of the osmotic agent at a temperature of $30^{\circ} \mathrm{C}$. The slices submitted to osmotic dehydration in these conditions were dried in microwaves and evaluated for their physical and chemical characteristics. The use of xylitol as an osmotic agent was more efficient than sucrose, providing a greater reduction in water, significantly influencing the retention of vitamin $\mathrm{C}$ content after microwave drying and presenting a lower water content.

\footnotetext{
Revista Verde

ISSN 1981-8203

Pombal, Paraíba, Brasil
}

v. 15, n.2, abr.-jun., p.183-192, 2020

doi: $10.18378 /$ rvads.v15i2.7811 


\section{INTRODUÇÃO}

As frutas são materiais biológicos que apresentam inúmeros compostos bioativos, com sabor e aroma atrativos para o consumo in natura e para sua utilização como matéria-prima em alimentos industrializados (CASTRO et al., 2018). A inserção de frutas na dieta humana representa um importante papel na prevenção de doenças, pois as frutas fornecem nutrientes que são essenciais para o bom funcionamento do organismo, como vitaminas, minerais e vários fitoquímicos (CHANG et al., 2016).

O mamão (Carica papaya L.) pertence à família das Caricaceae, consumido principalmente em sua forma fresca, porém com alto potencial para ser industrializado (ZERPACATANHO et al., 2017). Seu potencial para industrialização relaciona-se com as características nutricionais do fruto e a necessidade de minimizar perdas na pós-colheita. Esse é uma importante fonte de nutrientes funcionais, como minerais (cálcio, ferro, potássio, sódio), vitaminas (A, B1, B2, C) e carotenóides (licopeno, b-caroteno, b-criptoxantina) (SCHWEIGGERT et al., 2011). Porém, as perdas pós-colheita de mamão ocorrem ao longo de toda a cadeia produtiva, devido à rápida deterioração do fruto e seus componentes químicos, o que resulta em uma vida útil curta do produto fresco (UDOMKUN et al., 2015).

A maioria das frutas comuns são produzidas sazonalmente e, portanto, podem não estar disponíveis em condições frescas durante o ano, já quando processadas, essas frutas podem ser consumidas por um período de tempo maior (CHANG et al., 2016). Apesar do mamão ser um fruto encontrado em sua forma fresca durante o ano, o estudo de técnicas para o processamento possibilita um maior aproveitamento do produto, minimizando o desperdício de alimentos. A secagem é uma das técnicas mais amplamente utilizadas na conservação de frutas, pois possibilita a redução do teor de água, reduzindo a atividade microbiana e deterioração do produto. No entanto, um alto incremento da temperatura de secagem promove mudanças organolépticas e nutricionais em produtos alimentícios, que podem promover a redução da sua qualidade (GIAMPIERI et al., 2012).

Pré-tratamentos são aplicados com o objetivo de minimizar os danos ocasionados pelos tratamentos térmicos, melhorando assim a qualidade nutricional do produto final. A desidratação osmótica é um pré-tratamento térmico que é usado para remover uma parte da água dos alimentos, como frutas e legumes; é realizada imergindo os alimentos em soluções hipertônicas com alta pressão osmótica, como soluções de açúcares, sais ou álcoois (DEHGHANNYA et al., 2015). A sacarose é um agente osmótico amplamente usado no processo de desidratação osmótica de frutas obtendo resultados satisfatórios quando aos efeitos do seu uso, melhorando as características organolépticas e aumento a perda de água. No entanto, polióis, como xilitol e sorbitol, são solutos cada vez mais empregados nessa técnica. O xilitol é um poliol com cinco átomos de carbono e cinco grupos hidroxilo, de estrutura cristalina, encontrado em muitas frutas e vegetais, é tão doce quando a sacarose, porém menos calórico (RILEY et al., 2015). A principal vantagem do uso de polióis como agente osmótico é que o produto desidratado apresenta menor valor calórico e índice glicêmico do que o obtido quando a sacarose é utilizada (MENDONÇA et al., 2016). Porém, a deve-se analisar a sua eficiência quando a perda de água do fruto durante o processo de desidratação osmótica e comparar aos agentes osmóticos comumente usados, neste caso, a sacarose.

A comparação de diferentes agentes osmóticos no processo de desidratação osmótica de fatias de mamão sob iguais condições, permite criar alternativas para melhoramento do processo, aliando os efeitos desejáveis do processo com as vantagens do uso de agentes osmóticos como o xilitol. Além disso, o estudo das concentrações do agente osmótico combinado a diferentes temperaturas, torna possível o conhecimento das condições mais adequadas para otimização do processo de desidratação das fatias de mamão.

Apesar do processo de desidratação osmótica possuir inúmeros benefícios, a remoção de água do alimento durante o processo não é suficiente para garantir a sua estabilidade durante o armazenamento, sendo necessária a aplicação de um método de secagem complementar. A secagem convectiva é o método mais utilizado em frutas e vegetais; porém, apresenta baixa eficiência e longo tempo de secagem. Enquanto, a secagem por microondas tem várias vantagens sobre a secagem por convecção, como taxa de secagem mais alta, aquecimento mínimo em locais com menos água, reduzindo assim o superaquecimento de locais onde o aquecimento não é necessário (DEMIRAY et al., 2017). Diante dessas condições, objetivou-se com esse trabalho avaliar o efeito da temperatura e concentração de sacarose e xilitol na cinética de desidratação osmótica, e os efeitos da secagem complementar em micro-ondas nas características físicas e químicas de fatias de mamão papaia.

\section{MATERIAL E MÉTODOS}

A sacarose comercial (Cia União) e o xilitol (NUTRANATUS) assim como os frutos, foram adquiridos no comércio da cidade de Campina Grande, Paraíba. Os mamões papaia adquiridos foram selecionados quanto a coloração da casca, onde o estádio de maturação foi definido visualmente. Os mamões selecionados apresentavam entre 15 a $25 \%$ da superfície amarela, classificados como 1/4 de madura segundo Prates (2005), o qual classifica o percentual de cor amarela na casca dos frutos de mamoeiro nos seguintes estádios de maturação: estádio 0 verde (frutos crescidos e desenvolvidos com $100 \%$ da casca verde); estádio 1 - amadurecendo (início da mudança de cor da casca com 15\% amarelecida); estádio 2 - 1/4 madura (fruto com até $25 \%$ da superfície da casca amarela); estádio 3 - 1/2 madura (fruto com até $50 \%$ da superfície da casca amarela); estádio 4 $3 / 4$ madura (fruto com $50 \%-75 \%$ da superfície da casca amarela) e estádio 5 - madura (fruto com 76\% - 100\% da superfície da casca amarela e adequado para consumo). Os frutos foram sanitizados em solução de hipoclorito de sódio $\left(150 \mathrm{~m} . \mathrm{g} . \mathrm{L}^{-1} \mathrm{de}\right.$ cloro livre) durante 15 minutos, descascados e cortados em fatias de com espessura de $5,0 \mathrm{~mm}$. O corte das fatias de mamão orientado por medições com paquímetro da espessura e cortada com uma lâmina de aço inoxidável.

As soluções hipertônicas de sacarose e xilitol foram elaboradas nas concentrações de 7,8, 15,0, 32,5, 50,0 e 57,2 ${ }^{\circ}$ Brix. As concentrações dos agentes osmóticos foram estabelecidas com base em testes preliminares, onde foram testadas várias concentrações e observado as alterações nas características organolépticas e de perda de água das fatias de mamão. As soluções foram preparadas a partir da dissolução da 
sacarose e do xilitol em água destilada e agitadas até completa dissolução.

\section{Processo de desidratação osmótica}

As fatias de mamão foram completamente imersas nas soluções osmóticas, utilizando uma proporção de 1:10 (amostra/solução) determinada em julgamento preliminar. Os recipientes contendo o fruto e a solução osmótica foram inseridos em uma incubadora com temperatura controlada e agitador orbital, modelo TE-421, com agitação de $100 \mathrm{rpm}$ e temperaturas de $25,90,30,00,40,00,50,00$ e $54,10^{\circ} \mathrm{C}$. As temperaturas foram definidas com base em estudos como o de Aires et al. (2019) e Ferreira et al. (2020) onde foram estudas temperaturas de 40 e 60 ${ }^{\circ} \mathrm{C}$, para a maçã e temperaturas de 50,60 e $70{ }^{\circ} \mathrm{C}$ para cubos de mamão, respectivamente. Apesar das temperaturas citadas nas literaturas, temperaturas menores de $40{ }^{\circ} \mathrm{C}$ foram consideradas nesse estudo uma vez que é conhecido que temperaturas superiores aumenta a probabilidade de perdas na qualidade nutricional do fruto. As amostras foram retiradas da solução hipertônica após 30, 60, 90, 120, 150 e 180 min de imersão. Essas amostras foram lavadas rapidamente com água destilada para remoção da sacarose e xilitol aderente à superfície das fatias e o excesso de água foi absorvido em papel absorvente e posteriormente as amostras foram pesadas.

\section{Cinética de transferência de massa}

O modelo de Peleg (Equação 1) foi considerado para ajuste aos dados experimentais do parâmetro perda de água.

$$
\mathrm{PA}=\frac{\mathrm{t}}{\mathrm{a}+\mathrm{bt}}
$$

Em que, PA é a perda de água com o tempo (\%); a e b são constantes do modelo de Peleg e t é o tempo (min).

Determinação do teor de água, sólidos totais e perda de água

Os teores de água e sólidos totais foram determinados em estufa a $105^{\circ} \mathrm{C}$, até massa constante. Todas as análises foram realizadas em triplicada e o valor médio obtido para análise. Foi determinada a perda de água segundo a Equação 2 (KUCNER et al., 2013).

$$
\mathrm{PA}=\frac{\left(\mathrm{M}_{0}\left(1-\mathrm{S}_{0}\right)-\mathrm{M}_{\mathrm{i}}\left(1-\mathrm{S}_{\mathrm{i}}\right)\right)}{\mathrm{M}_{0} \mathrm{~S}_{0}}
$$

Em que: PA é a perda de água (\%); $\mathrm{M}_{0}$ é a massa inicial da amostra $(\mathrm{g}) ; \mathrm{M}_{i}$ é a massa da amostra após desidratação osmótica (g); $\mathrm{S}_{0}$ é os sólidos totais inicial da amostra ( $\mathrm{g}$ de água / $\mathrm{g}$ de amostra) e $S_{i}$ é os sólidos totais após a desidratação osmótica (g de água / g de amostra).

\section{Secagem por micro-ondas}

Os fornos de micro-ondas têm sido utilizados com sucesso como fonte de calor na indústria de alimentos, porque as microondas penetram diretamente nos produtos, causando rápido aquecimento interno através da rotação de dipolos e condutância iônica nos materiais da matriz (FAN et al., 2019). Para a secagem foi utilizado um equipamento de micro-ondas, modelo MM25EL2VB, com potência de 800 Watts. Durante a secagem, foram realizadas pesagens em intervalos de tempo de 30 segundos até peso constante, para acompanhamento da perda de água com o tempo de secagem. $\mathrm{O}$ processo de secagem foi interrompido quando não foi observada variações na massa por duas medições consecutivas (SHARMA, PRASAD, 2004). Os volumes das fatias foram determinados em intervalos de 60 segundos, por medidas do comprimento, largura e espessura, usando um paquímetro digital.

\section{Características físicas químicas}

Foram determinados o teor de água (\% b.u), sólidos totais (\%), pH, Acidez total titulável (\% de ácido cítrico) (IAL, 2008), sólidos solúveis totais $\left({ }^{\circ}\right.$ Brix) utilizando um refratômetro portátil Modelo rt-95, ratio, açúcares redutores (MILLER, 1959) e vitamina C (STROHECKER, HENNING, 1967) das fatias de mamão in natura e secas em micro-ondas após o processo de desidratação osmótica com xilitol e sacarose.

\section{Análise estatística}

Foi realizado um planejamento fatorial $2^{2}$, com quatro pontos axiais e três repetições no ponto central, totalizando 11 experimentos para cada solução osmótica. Os níveis dos fatores concentração de sólidos solúveis totais $\left({ }^{\circ}\right.$ Brix $)$ e temperatura de incubação $\left({ }^{\circ} \mathrm{C}\right)$ foram definidas de acordo com o planejamento experimental apresentado na Tabela 1.

Tabela 1. Matriz do planejamento experimental com valores reais das variáveis independentes do processo de desidratação osmótica das fatias de mamão.

\begin{tabular}{ccc}
\hline Experimento & $\begin{array}{c}\text { Concentração do agente } \\
\text { osmótico }\left({ }^{\circ} \text { Brix }\right)\end{array}$ & $\begin{array}{c}\text { Temperatura } \\
\left({ }^{\circ} \mathrm{C}\right)\end{array}$ \\
\hline 1 & 15,00 & 30,00 \\
2 & 15,00 & 50,00 \\
3 & 50,00 & 30,00 \\
4 & 50,00 & 50,00 \\
5 & 7,80 & 40,00 \\
6 & 57,20 & 40,00 \\
7 & 32,50 & 25,90 \\
8 & 32,50 & 54,10 \\
9 & 32,50 & 40,00 \\
10 & 32,50 & 40,00 \\
11 & 32,50 & 40,00 \\
\hline
\end{tabular}

Os dados da desidratação osmótica das fatias de mamão foram analisados conforme a metodologia de superfície de resposta, a qual, assume que existe uma função polinomial (Equação 3) que se relaciona as respostas as variáveis independentes.

$$
y=\beta_{0}+\beta_{1} x_{1}+\beta_{2} x_{2}+\beta_{3} x_{1} x_{2}+\beta_{4} x_{1}^{2}+\beta_{5} x_{2}^{2}
$$

Em que, $y$ é a resposta ou variável dependente, $x_{1}$ e $x_{2}$ são as variáveis independentes; $\beta_{\mathrm{n}}$ são constantes ajustáveis.

O teste estatístico de análise de variância (ANOVA) foi desenvolvido com um nível de confiança de $95 \%$, que inclui a significância estatística de cada termo do modelo ajustável (valor-p), os efeitos estimados em cada termo $\left(\beta_{\mathrm{n}}\right)$, o coeficiente de determinação do modelo $\left(\mathrm{R}^{2}>0,90\right)$, a fim de estabelecer a precisão do modelo usando o software Statistica 7.0 (STATSOFT, 2004).

Os modelos foram apresentados com os termos independente da equação estatisticamente significativos. Os termos não significativos do modelo foram desconsiderados uma vez que não tem influência significativa para a resposta ou variável independente.

Os resultados da caracterização do mamão in natura e secos 
por micro-ondas para cada agente osmóticos foram submetidos a análise de variância (ANOVA), utilizando o teste de comparação de Tukey $1 \%$ de probabilidade. Esses cálculos foram realizados usando o software Assistat 7.7 (SILVA; AZEVEDO, 2016).

\section{RESULTADOS E DISCUSSÃO}

\section{Cinética de transferência de massa}

O modelo de Peleg se ajustou aos dados experimentais da perda de água das fatias de mamão desidratadas osmoticamente, com $\mathrm{R}^{2}$ maior que $99,0 \%$ para todos os experimentos com o xilitol e superior a $98,0 \%$ para os experimentos com a sacarose (Tabela 2).

Ao analisar os resultados da Tabela 2, foi visto que o parâmetro 'a' aumenta nas maiores temperaturas, para ambos os agentes osmóticos. Além da temperatura, a concentração do agente osmótico foi influente nesse parâmetro, porém, em menor proporção. Os menores valores de 'a' obtidos pelo modelo de Peleg foram obtidos nos experimentos 7, 1 e 3, tanto para o xilitol como a sacarose. $\mathrm{O}$ menor valor foi o do experimento 7 , neste foram estudadas as concentrações de $32,50 \%$ do agente osmótico, na temperatura de $25,90{ }^{\circ} \mathrm{C}$. O menor valor de 'a' se refere ao recíproco da taxa de transferência de massa, o que nos diz que no experimento 7 , se obteve a maior taxa de transferência de água, para ambos os agentes osmóticos. O parâmetro 'b' apresentou baixos valores, o que é esperado, uma vez que se refere ao recíproco da composição de equilíbrio.

Tabela 2. Parâmetros de ajuste $(a, b)$ e coeficiente de determinação $\left(R^{2}\right)$ do modelo de Peleg para os dados de perda de água das fatias de mamão para cada agente osmótico.

\begin{tabular}{ccccccc}
\hline \multirow{2}{*}{ Experimentos } & \multicolumn{3}{c}{ Xilitol } & \multicolumn{3}{c}{ Sacarose } \\
\cline { 2 - 7 } & $\mathrm{a}$ & $\mathrm{b}$ & $\mathrm{R}^{2}$ & $\mathrm{a}$ & $\mathrm{B}$ & $\mathrm{R}^{2}$ \\
\hline 1 & 17,41980 & 0,146388 & 99,97 & 14,17831 & 0,219099 & 99,89 \\
2 & 31,82486 & 0,185327 & 99,14 & 54,99840 & 0,181817 & 98,90 \\
3 & 17,46692 & 0,115912 & 99,94 & 16,32320 & 0,208097 & 99,49 \\
4 & 31,74318 & 0,124258 & 99,36 & 37,19568 & 0,128343 & 99,37 \\
5 & 29,90304 & 0,216470 & 99,97 & 23,58552 & 0,359885 & 99,94 \\
6 & 30,22829 & 0,118300 & 99,36 & 35,56699 & 0,122677 & 99,37 \\
7 & 16,47679 & 0,138381 & 99,97 & 13,47882 & 0,208006 & 99,89 \\
8 & 26,15309 & 0,173455 & 99,97 & 28,59023 & 0,311974 & 99,74 \\
9 & 45,15396 & 0,392990 & 99,72 & 81,26680 & 0,390450 & 98,98 \\
10 & 61,37301 & 0,323302 & 99,78 & 73,86503 & 1,048232 & 99,95 \\
11 & 53,68636 & 0,356495 & 99,75 & 97,94301 & 0,567921 & 99,50 \\
\hline
\end{tabular}

*Experimentos: $1\left(15,00{ }^{\circ}\right.$ Brix e $\left.30,00{ }^{\circ} \mathrm{C}\right) ; 2\left(15,00{ }^{\circ}\right.$ Brix e $\left.50,00{ }^{\circ} \mathrm{C}\right) ; 3\left(50,00{ }^{\circ}\right.$ Brix e $\left.30,00{ }^{\circ} \mathrm{C}\right) ; 4\left(50,00{ }^{\circ}\right.$ Brix e $\left.50,00{ }^{\circ} \mathrm{C}\right) ; 5\left(7,80{ }^{\circ}\right.$ Brix e $\left.40,00{ }^{\circ} \mathrm{C}\right) ; 6$ $\left(57,50{ }^{\circ}\right.$ Brix e $\left.40,00^{\circ} \mathrm{C}\right) ; 7\left(32,50{ }^{\circ}\right.$ Brix e $\left.25,90{ }^{\circ} \mathrm{C}\right) ; 8\left(32,50{ }^{\circ}\right.$ Brix e $\left.54,10{ }^{\circ} \mathrm{C}\right) ; 9\left(32,50{ }^{\circ}\right.$ Brix e $\left.40,00{ }^{\circ} \mathrm{C}\right) ; 10\left(32,50{ }^{\circ} \mathrm{Brix}\right.$ e $\left.40,00{ }^{\circ} \mathrm{C}\right)$ e $11\left(32,50{ }^{\circ} \mathrm{Brix}\right.$ e $\left.40,00^{\circ} \mathrm{C}\right)$.

Verificou-se que a perda de água nas fatias de mamão aumentou com o tempo de desidratação osmótica em todos os experimentos (Figura 1). Na Fugira 1A, observa-se que a perda de água das fatias de mamão desidratada osmoticamente com xilitol foi superior aos resultados das amostras tradas com sacarose (Figura 1B).

Figura 1. Perda de água de fatias de mamão com ajuste do modelo de Peleg para os agentes osmóticos: (A) xilitol e (B) sacarose.
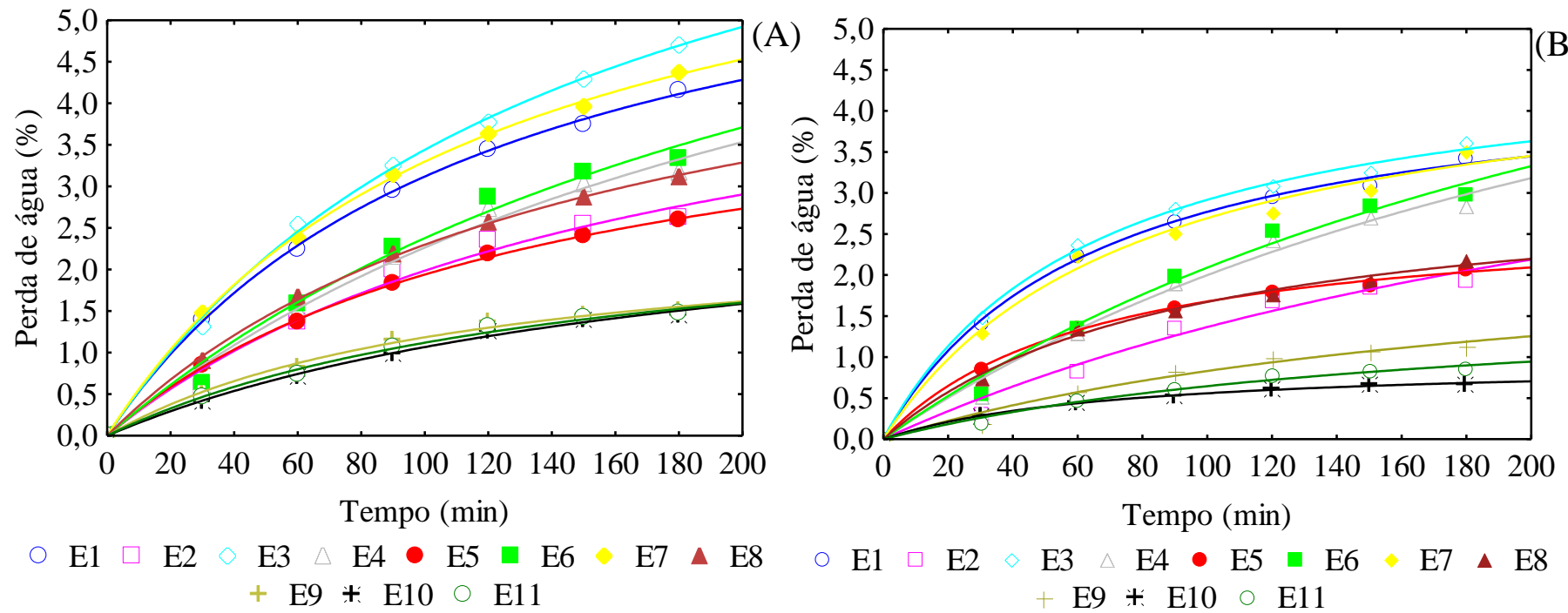

*Experimentos: E1 $\left(15,00{ }^{\circ}\right.$ Brix e $\left.30,00{ }^{\circ} \mathrm{C}\right)$; E2 $\left(15,00{ }^{\circ}\right.$ Brix e 50,00 $\left.{ }^{\circ} \mathrm{C}\right)$; E3 $\left(50,00{ }^{\circ}\right.$ Brix e $\left.30,00{ }^{\circ} \mathrm{C}\right)$; E4 $\left(50,00{ }^{\circ} \mathrm{Brix}\right.$ e $\left.50,00{ }^{\circ} \mathrm{C}\right)$; E5 $\left(7,80{ }^{\circ} \mathrm{Brix}\right.$ e $\left.40,00{ }^{\circ} \mathrm{C}\right)$; E6 $\left(57,50{ }^{\circ}\right.$ Brix e 40,00 $\left.{ }^{\circ} \mathrm{C}\right)$; E7 $\left(32,50{ }^{\circ}\right.$ Brix e $\left.25,90{ }^{\circ} \mathrm{C}\right)$; E8 $\left(32,50{ }^{\circ}\right.$ Brix e $\left.54,10{ }^{\circ} \mathrm{C}\right)$; E9 $\left(32,50{ }^{\circ}\right.$ Brix e 40,00 $\left.{ }^{\circ} \mathrm{C}\right)$; E10 $\left(32,50{ }^{\circ}\right.$ Brix e $\left.40,00{ }^{\circ} \mathrm{C}\right)$ e E11 $\left(32,50{ }^{\circ}\right.$ Brix e $\left.40,00{ }^{\circ} \mathrm{C}\right)$. 
O aumento da perda de água nas fatias de mamão durante o processo de desidratação osmótica está em concordância com os resultados observados em estudo da cinética de desidratação osmótica de manga (SULISTYAWATI et al., 2020) e em cinética de desidratação osmótica de Terung Asam (Solanum lasiocarpum Dunal) (CHIU et al., 2017). No entanto, os experimentos submetidos a desidratação osmótica utilizando como agente osmótico a sacarose, mostrou rápido aumento da perda de água nos primeiros 90 minutos, comparado com os experimentos utilizando o xilitol como agente osmótico, que apresentou o aumento quase linear com o tempo. Comportamento semelhante aos experimentos com a sacarose foi relatado por Chiu et al. (2017) e colaboradores, que afirmaram que a grande força motriz osmótica entre a seiva das fatias de Terung Asam e a solução hipertônica circundante promoveu a rápida remoção da água do Terung Asam para o meio osmótico durante a fase inicial do processo osmótico. No entanto, a remoção é atribuída à solução hipertônica, a seiva não alterou a concentração da solução, porém houve interação, o que as vezes não ocorre.

Observou-se que o xilitol como agente osmótico contribuiu para uma maior remoção da água contida nas fatias de mamão (Figura 1A), comparado ao convencional uso da sacarose (Figura 1B). O que reflete uma maior eficácia em termos de perda de água, isso também foi observado por Cichowska et al. (2019) ao estudar o uso de solutos não convencionais como agentes osmóticos.

Os efeitos da concentração do agente osmótico e da temperatura sobre a perda de água pode ser observado na Figura 2. Na Figura $2 \mathrm{~A}$ e $2 \mathrm{~B}$, observa-se que tanto para o xilitol como a sacarose, na temperatura de $40{ }^{\circ} \mathrm{C}$, foram obtidas as menores taxas de perda de água, independente da concentração do agente osmótico, isso é evidenciado ao analisar o termo linear da temperatura no modelo, mostrando um efeito negativo (Equações 4 e 5). Enquanto, os experimentos em que foram analisados os níveis extremos, apresentam a maior perda de água, a exemplo, o experimento $3\left(50,0^{\circ}\right.$ Brix e $\left.30^{\circ} \mathrm{C}\right)$ utilizando o xilitol, obtendo uma perda de $4,69 \%$, e utilizando a sacarose, obteve uma perda de água de 3,61\%; como pode ser observado a partir dos efeitos dos termos linear e quadráticos da concentração do agente osmótico e da temperatura no modelo, mostrando que ao aumentar a concentração do agente osmótico, tem-se o aumento da perda de água. Durante a desidratação osmótica a taxa de perda de água é diretamente proporcional a: concentração da solução osmótica; tempo de imersão; temperatura; relação de peso da solução de alimentação; agitação; e depende da estrutura dos alimentos, tamanho e geometria dos sólidos e da área de troca de massa e pressão do sistema (BROCHIER et al., 2019). Apesar da maior perda de água ter sido observada no experimento 3 , os experimentos 7 e 1, com menores concentrações dos agentes osmóticos também apresentaram bons resultados com taxa de perda de água próximo ao observado no experimento 3.Vale destacar que para o estudo foi utilizado fatias finas de mamão 1/4 de maduro, onde a estrutura no produto é um dos fatores determinantes no processo de desidratação. Os modelos polinomiais ajustados aos resultados da perda de água das fatias de mamão são apresentados apenas com os parâmetros estatisticamente significativos na Equação 4, para o xilitol e na Equação 5, para a sacarose.

$$
\mathrm{PA}=25,575-0,159 \times \mathrm{CX}+0,003 \times \mathrm{CX}^{2}-1,028 \times \mathrm{T}+0,012 \times \mathrm{T}^{2}
$$

$$
\mathrm{PA}=22,435-0,169 \times \mathrm{CS}+0,003 \times \mathrm{CS}^{2}-0,901 \times \mathrm{T}+0,011 \times \mathrm{T}^{2}
$$

$\mathrm{R}^{2}=96,67 \%$

Em que, PA é a perda de água $\left(\mathrm{g} . \mathrm{g}^{-1}\right)$; CX é a concentração de xilitol ( ${ }^{\circ}$ Brix), CS é a concentração de sacarose $\left({ }^{\circ}\right.$ Brix) e T é a temperatura $\left({ }^{\circ} \mathrm{C}\right)$.

Figura 2. Efeito da concentração do agente osmótico e temperatura na perda de água para o (A) xilitol, (B) sacarose.


Esse comportamento observado para a perda de água das fatias de mamão durante a desidratação osmótica corrobora com os apresentados por Islam et al. (2019) e Najafi et al. (2014) ao estudarem a influência da desidratação osmótica na cinética de transferência de massa e retenção da qualidade do mamão maduro (Carica papaya L) durante a secagem, e no processo de desidratação osmótica utilizando solução de sacarose a 
temperatura amena na transferência de massa e nos atributos de qualidade de pitaya vermelha (Hylocereus polyrhizusis), respectivamente. Nesses estudos, foi observando o aumento da remoção de água com o aumento da concentração de sacarose na solução hipertônica.

Os efeitos das variações da concentração do agente osmótico e da temperatura sobre o teor de água e sólidos totais das fatias de mamão papaia são apresentados na Figura 3.

$\mathrm{O}$ uso do xilitol como agente osmótico (Figura 3A) promoveu maior redução do teor de água das fatias de mamão, como previsto ao analisar as demais respostas a influências das variáveis independentes, comparado com o uso da sacarose (Figura 3B). Obtendo teores de água em base úmida entre $68,59 \%$ no experimento $3\left(50,0{ }^{\circ}\right.$ Brix e $\left.30,0{ }^{\circ} \mathrm{C}\right)$ e $84,41 \%$ no experimento $10\left(32,5^{\circ}\right.$ Brix e $\left.40,0^{\circ} \mathrm{C}\right)$, para as fatias de mamão tratadas com xilitol. Enquanto, as fatias de mamão tratadas como sacarose, apresentaram valores entre $76,55 \%$ no experimento 3 $\left(50,0{ }^{\circ}\right.$ Brix e $\left.30,0^{\circ} \mathrm{C}\right)$ a $86,11 \%$ no experimento $10\left(32,5^{\circ}\right.$ Brix e 40,0 ${ }^{\circ} \mathrm{C}$ ). Esses dados evidenciam a eficácia do xilitol como agente osmótico na remoção de água de fatias de mamão, proporcionando uma alternativa ao convencional uso da sacarose nos processos de desidratação osmótica.

Figura 3. Efeito da concentração do agente osmótico e temperatura no teor de água para o (A) xilitol, (B) sacarose e sólidos totais para (C) xilitol e (D) sacarose.

\section{(A)}

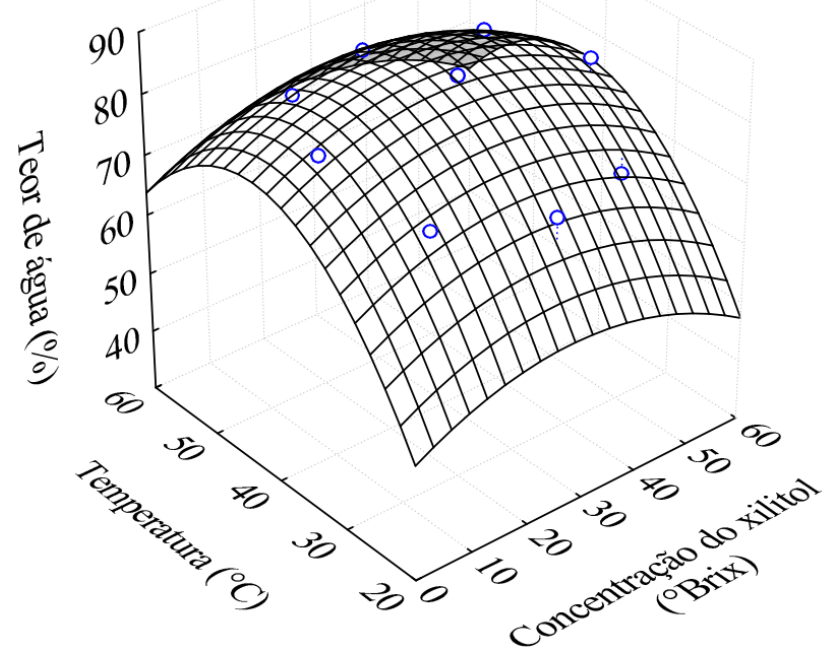

(C)

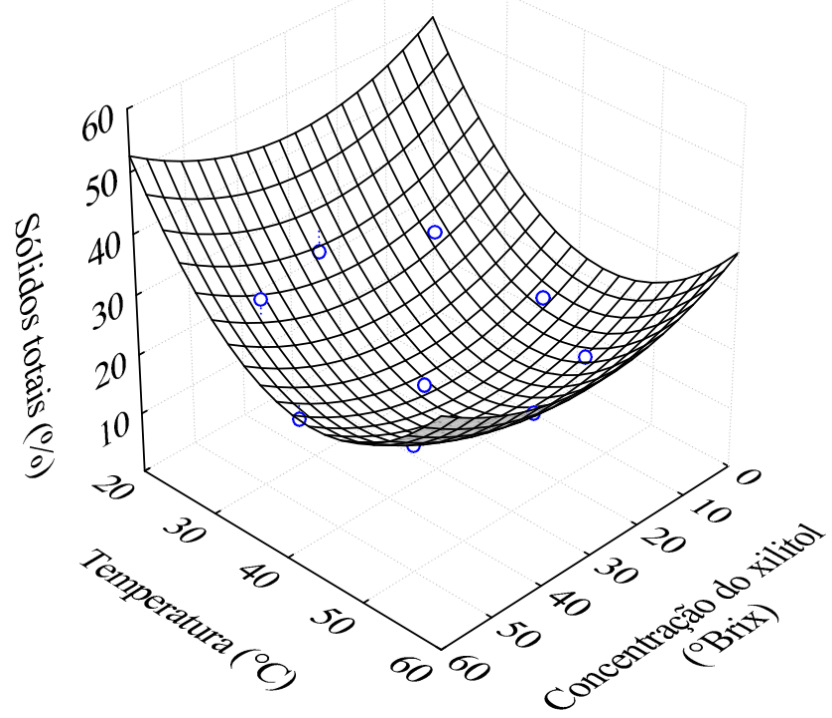

As Equações 6 e 7, apresentam os modelos polinomiais ajustados aos dados do teor de água sobre os experimentos com xilitol e sacarose. Os termos apresentados foram estatisticamente significativos.

$\mathrm{TA}=-18,810+0,541 \times \mathrm{CX}-0,009 \times \mathrm{CX}^{2}+4,425 \times \mathrm{T}-0,051 \times \mathrm{T}^{2} \quad$ (6) $\mathrm{R}^{2}=94,44 \%$
(B)
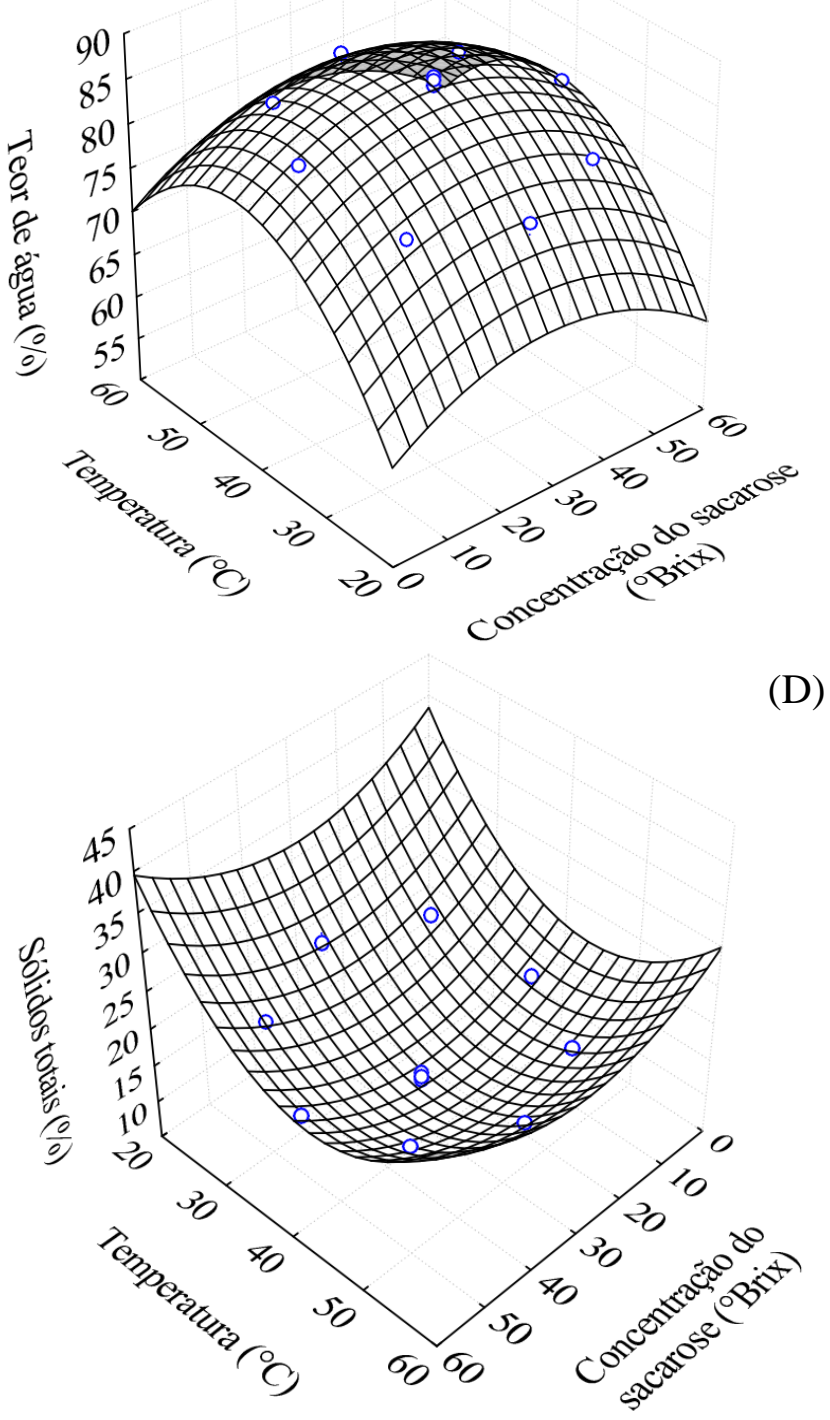

$\mathrm{TA}=17,482+0,466 \times \mathrm{CS}+0,008 \times \mathrm{CS}^{2}+2,865 \times \mathrm{T}-0,033 \times \mathrm{T}^{2}$

$\mathrm{R}^{2}=96,93 \%$

Quanto aos sólidos totais, um comportamento inverso ao teor de água foi observado, uma vez que, ao reduzir o teor de água das fatias de mamão, ocorreu a concentração dos sólidos 
totais, como mostra a Figura 3C para o xilitol e a Figura 3D para a sacarose. A influência da concentração do agente osmótico e da temperatura do processo, resultou em fatias de mamão com conteúdo de sólidos totais variando entre $31,41 \%$ a $15,59 \%$ utilizando o xilitol, e de $23,45 \%$ a $13,89 \%$ utilizando a sacarose como agente osmótico, ambos os resultados foram obtidos nos experimentos 3 e 10 para os dois agentes osmóticos estudados.

Os modelos polinomiais ajustados aos resultados obtidos para o conteúdo de sólidos totais, sobre os efeitos das variáveis independentes estão apresentados na Equação 8, para o xilitol e na Equação 9, para a sacarose. Os termos apresentados foram estatisticamente significativos.

$$
\mathrm{ST}=118,810-0,541 \mathrm{CX}+0,009 \times \mathrm{CX}^{2}-4,425 \times \mathrm{T}+0,051 \times \mathrm{T}^{2}
$$

$$
\mathrm{ST}=82,518-0,466 \times \mathrm{CS}+0,008 \times \mathrm{CS}^{2}-2,865 \times \mathrm{T}+0,033 \times \mathrm{T}^{2}
$$

$$
\mathrm{R}^{2}=96,93 \%
$$

\section{Secagem em micro-ondas}

A partir do estudo da desidratação osmótica das fatias de mamão, foi possível estabelecer as melhores condições as quais ocorreu a maior remoção de água das fatias, para posterior secagem complementar em micro-ondas. Para isso, foi escolhida as condições com $50^{\circ}$ Brix do agente osmótico e temperatura de $30{ }^{\circ} \mathrm{C}$, para ambos os agentes osmótico.
A Figura 4, mostra a influência da secagem em micro-ondas na razão do teor de água e no volume das fatias de mamão papaia pré-desidratadas osmoticamente com xilitol e sacarose durante o tempo de secagem.

$\mathrm{Na}$ Figura 4A, observa-se que as fatias de mamão submetidas ao tratamento de desidratação osmótica com xilitol obtiveram o maior tempo de secagem até chegar ao equilíbrio termodinâmico. Enquanto, a tratada com sacarose, atingiu o equilíbrio termodinâmico no tempo de 420 segundos. Porém, observa-se que para as fatias tratadas com xilitol, obteve uma taxa de secagem maior que as fatias tratadas como sacarose (Figura 4A). Já quanto ao volume (Figura 4B), observou-se uma redução gradual do volume das fatias de mamão, tanto nas tratadas como xilitol como as tratadas com sacarose. Durante a secagem por micro-ondas se observou a formação de bolsas de ar na superfície das fatias de mamão, as bolsas de ar refletem a rápida evaporação da água e a resistência da estrutura da superfície das fatias de mamão. A rápida evaporação da água reduz o encolhimento dos produtos alimentícios quando comparado a outras técnicas de secagem. Lopes e Pereira, (2015) ao estudarem o encolhimento na secagem convectiva de abacaxi com aplicação de micro-ondas variável, concluiu que o encolhimento observado foi linear com o decréscimo de umidade. Entretanto, há indício de que a elevação da potência proporciona pode reduzir o encolhimento.

Figura 4. Razão do teor de água (A) e volume (B) das fatias de mamão pré-desidratadas osmoticamente com xilitol e sacarose durante o tempo de secagem.

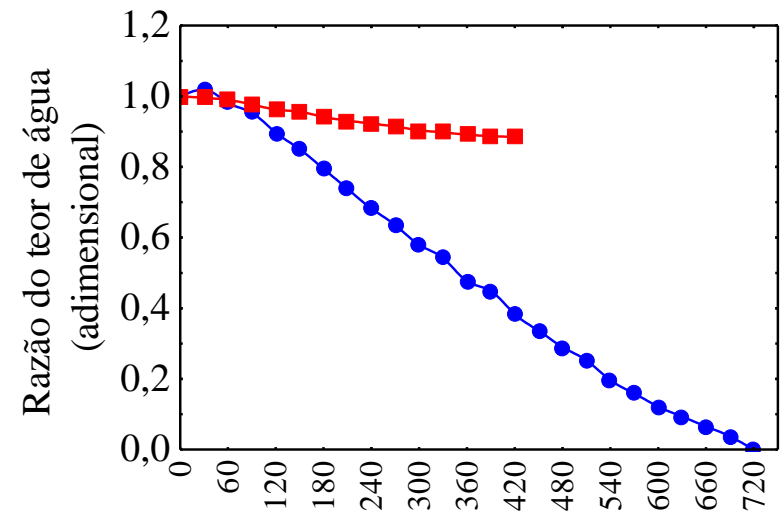

Tempo (s)
(A)

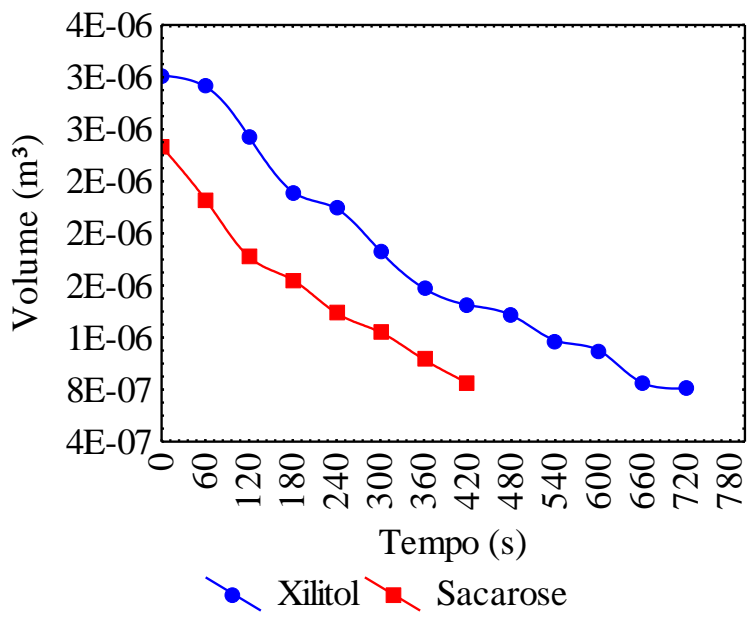

(B)

marmelo, relatou o efeito da secagem em micro-ondas sobre a qualidade sensorial do produto (cor e textura), onde foi relatado pontos escuros na superfície do produto.

As fatias de mamão foram analisadas in natura e após secagem em micro-ondas pré-desidratadas sob as condições que apresentou as melhores taxas de perda de água, experimento 3 $\left(50,0^{\circ}\right.$ Brix e $\left.30,0^{\circ} \mathrm{C}\right)$, e os resultados obtidos estão apresentados na Tabela 3. Para análise das características físicas e químicas das amostras secas, o processo de secagem foi interrompido no tempo de 480 segundo, onde, a partir desse tempo, foi observado alterações consideráveis no aspecto visual e estrutural das fatias (pontos de carbonização). 
Tabela 3. Caracterização físico-química das fatias de mamão papaia in natura e secas em micro-ondas para cada agente osmótico.

\begin{tabular}{llll}
\hline \multicolumn{1}{c}{ Parâmetros } & \multicolumn{3}{c}{ Experimentos } \\
\cline { 2 - 4 } & in natura & Xilitol & Sacarose \\
\hline Teor de água (\% b.u) & $89,22 \mathrm{a}$ & $39,52 \mathrm{c}$ & $55,05 \mathrm{~b}$ \\
Sólidos Totais (\%) & $10,78 \mathrm{c}$ & $60,48 \mathrm{a}$ & $45,09 \mathrm{~b}$ \\
Sólidos Solúveis Totais ( ${ }^{\circ}$ Brix) & $13,72 \mathrm{c}$ & $44,06 \mathrm{~b}$ & $53,00 \mathrm{a}$ \\
$\mathrm{pH}$ & $5,63 \mathrm{a}$ & $4,93 \mathrm{~b}$ & $4,80 \mathrm{~b}$ \\
Acidez Total Titulável (\% de ácido cítrico) & $0,23 \mathrm{~b}$ & $0,67 \mathrm{a}$ & $0,67 \mathrm{a}$ \\
Ratio & $58,81 \mathrm{~b}$ & $70,35 \mathrm{a}$ & $79,42 \mathrm{a}$ \\
Açucares Redutores (g glicose.100. $\left.\mathrm{mL}^{-1}\right)$ & $9,07 \mathrm{c}$ & $32,47 \mathrm{~b}$ & $51,57 \mathrm{a}$ \\
Vitamina C (\% de ácido ascórbico) & $37,36 \mathrm{a}$ & $29,75 \mathrm{~b}$ & $20,94 \mathrm{c}$ \\
\hline
\end{tabular}

*Médias seguidas pela mesma letra na linha, não diferem estatisticamente entre si pelo teste de Tukey a 5\% de probabilidade.

Os teores de água das fatias de mamão apresentaram diferença significativa $(\mathrm{p}<0,01)$ entre os tratamentos. Foi observado que as fatias de mamão tratadas como o xilitol apresentaram valores inferiores com relação ao teor de água após a secagem e consequentemente valores superiores com relação ao teor de sólidos totais, quando comparadas aos demais experimentos. Os teores de água obtidos após a secagem em micro-ondas, neste estudo, foram superiores a estudos de desidratação de frutas em micro-ondas. A exemplo, Rodriguéz et al. (2019) ao estudar a desidratação de framboesas em microondas com potência selecionada de $350 \mathrm{~W}$ (densidade de potência $7,5 \mathrm{~W} \cdot \mathrm{g}^{-1}$ ), onde encontraram um teor de água de $21,26 \%$, e Veja-Gálvez et al. (2019) no estudo das características químicas e bioativa do mamão (Vasconcellea pubescens) sob diferentes tecnologias de secagem, encontrado um valor de $21,57 \%$ para o mamão submetido a secagem solar, cujas condições foram variáveis durante o dia, registando temperaturas entre 31,0 a $49,9^{\circ} \mathrm{C}$ e umidade do ar entre 20 a $45 \%$.

O conteúdo de sólidos solúveis totais nas fatias in natura foi semelhante aos encontrados por Kandasamy et al. (2014) para a polpa de mamão (Carica papaya L.) fresca (13,0 ${ }^{\circ}$ Brix), Barragán-Iglesias et al. (2019), para cubos de mamão fresco (12,0 ${ }^{\circ}$ Brix) e Nunes et al. (2017), ao estudar o mamão formosa $\left(11,35{ }^{\circ}\right.$ Brix $)$. Após o processo de secagem em micro-ondas, observa-se o aumento significativo dos sólidos solúveis totais, especialmente nas fatias tratadas com a sacarose, resultado do contato das fatias com o soluto contido nas soluções hipertónicas utilizadas no tratamento osmótica, devido a transferência de massa.

Através da Tabela 2, pode-se observar que o processo de secagem em micro-ondas provocou a redução do $\mathrm{pH}$ e o aumento da acidez do produto, havendo diferença estatística significativa entre as amostras desidratadas e a amostras in natura. Esse aumento está relacionado a remoção da água, resultando na maior concentração dos ácidos orgânicos presentes nas fatias de mamão. A concentração dos ácidos orgânicos com a secagem resulta em alterações sensoriais desejáveis para o produto, assim como, um ambiente ácido dificulta o desenvolvimento de microorganismo indesejáveis durante o armazenamento do produto. Comportamento similar foi reportado por Santos et al. (2019) ao realizarem a cinética de secagem convectiva de fatias de pêssego, observaram que o acréscimo da temperatura aplicada ao processo de secagem proporcionou redução do $\mathrm{pH}$ e aumento da acidez do produto, apresentando valores de 1,26 a $1,82 \%$ e $\mathrm{pH}$ de 6,32 a 6,52. Com relação aos agentes osmóticos, não foi observada diferença significativa entre as fatias tratadas com o xilitol e a sacarose.

Com relação ao parâmetro ratio, observou-se um aumento significativo $(\mathrm{p}<0,01)$ para as fatias de mamão secas comparadas com a amostra in natura; porém, entre as amostras secas, tratadas como xilitol e sacarose, não foi observado diferença estatística. O aumento desse parâmetro está relacionado ao aumento dos sólidos solúveis totais ( ${ }^{\circ}$ Brix), que se deu devido a prédesidratação osmótica e concentração dos constituintes pela secagem, o que indica um produto com sabor mais adocicado. Variação nos valores do ratio foram relatados por Santana et al. (2004), ao analisar cinco genótipos do Banco Ativo de Germoplasma de Mamão (Carica papaya L.) da EMBRAPACNPMF, onde observou variações entre 173,41 e 68,26, conforme o genótipo no mamão estudado. Resultados inferiores a estes foram observadas neste estudo para o fruto in natura. As diferenças encontradas entre os valores relatados na literatura, pode estar relacionado com fatores intrínsecos e extrínsecos que influenciam a composição dos frutos, podendo citar a variedade do fruto e o estádio de maturação.

Quanto aos açúcares redutores das fatias de mamão, o resultado obtido para as fatias de mamão in natura está em concordância com os relatados por Santana et al. (2004), cujos resultados obtidos variaram de 9,5 a 11,3\%, conforme o genótipo do mamão. Em relação aos açúcares redutores das fatias de mamão secas, observou-se o aumento desse parâmetro, diferindo entre os tratamentos com xilitol e sacarose. O maior conteúdo de açúcares redutores foi observado para as fatias pré-desidratadas como sacarose. O mesmo ocorreu com o teor de sólidos solúveis totais, justificado devido a remoção da água e concentração dos sólidos nas fatias secas em micro-ondas.

$\mathrm{O}$ teor de vitamina $\mathrm{C}$ inicial nas fatias de mamão foi inferior aos observados em algumas pesquisas, observando uma variação conforme o genótipo do mamão. Outra justificativa para essa é o estádio de maturação do fruto. Vega-Gálvez et al. (2019), encontraram o teor inicial de vitamina $C$ de $7,27 \mathrm{mg} \cdot \mathrm{g}^{-1}$ para o mamão fresco. Já para o mamão submetido a diferentes técnicas de secagem, foi relatado valores de $2,14 \mathrm{mg}^{-\mathrm{g}^{-1}}$ no processo de secagem solar, a 5,39 mg. $\mathrm{g}^{-1}$ no mamão desidratado pelo método de secagem a vácuo. Neste estudo foi observado que as amostras submetidas a secagem em micro-ondas apresentaram uma redução estatisticamente significativa $(\mathrm{p}<0,01)$, comparado as fatias de mamão in natura, o que era previsto, devido à alta sensibilidade deste componente ao calor; porém, as fatias tratadas com o xilitol, apresentaram uma maior retenção da vitamina $\mathrm{C}$ após o processo de secagem comparado as fatias de 
mamão pré-desidratadas com sacarose. Isso pode ser resultado da maior estabilidade química do xilitol, além de que, devido à ausência de grupos aldeídos ou cetônicos em suas moléculas, o xilitol não participa de reações com aminoácidos, proporcionando a conservação de produtos alimentícios (MUSSATTO; ROBERTO, 2002).

\section{CONCLUSÕES}

O uso do xilitol como agente osmótico no processo de desidratação osmótica é eficaz na redução da água presente nas fatias de mamão, com resultados superiores ao uso da sacarose. E, o uso do agente osmótico xilitol em fatias de mamão com 50 ${ }^{\circ}$ Brix em temperatura de $30{ }^{\circ} \mathrm{C}$ é a melhor condição na remoção de água empregando a desidratação osmótica.

A secagem complementar em micro-ondas das fatias de mamão pré-desidratadas osmoticamente é eficiente na rápida remoção da água resultante no produto pré-tratado, em vista do curto período de tempo do processo, comparado ao tempo de secagem empregando em outras técnicas como a secagem convectiva.

O uso do xilitol como agente osmótico apresenta bons resultados, com menor teor de água e maior preservação da vitamina $\mathrm{C}$, comparado ao uso da sacarose.

\section{REFERÊNCIAS}

AIRES, K. L. C. de A., SILVA, W. P. da, AIRES, J. E. de FARIAS, SILVA JÚNIOR, A. F. da, SILVA, C. M. D. P. da S. Convective drying of osmotically dehydrated apples described by three-dimensional numerical solution of the diffusion equation with analysis of water effective diffusivity spatial distribution. Drying Technology, v. 37, n. 16, p. 2034-2046, 2019. 10.1080/07373937.2018.1549565

AZUARA, E.; BERITAIN, C. I.; GARCIA, H. S. Development of a mathematical model to predict kinetics of osmotic dehydration. Journal of food science and technology (Mysore), v. 29, n. 4, p. 239-242, 1992.

BARRAGÁN-IGLESIAS， J.; RODRÍGUEZ-RAMÍREZ，J.; SABLANI, S. S.; MÉNDEZ-LAGUNAS, L. L. Texture analysis of dried papaya (Carica papaya L., cv. Maradol) pretreated with calcium and osmotic dehydration. Drying Technology, v. 37, n. 7, p. 906-919, 2019. 10.1080/07373937.2018.1473420

BROCHIER, B.; INÁCIO, J. M.; NOREÑA, C. P. Z. Study of osmotic dehydration of kiwi fruit using sucrose solution. Brazilian Journal of Food Technology, v. 22, 2019. $\underline{10.1590 / 1981-6723.14618}$

CASTRO, A.; MAYORGA, E.; MORENO, F. Mathematical modelling of convective drying of fruits: A review. Journal of Food Engineering, v. 223, p. 152-167, 2018. 10.1016/j.jfoodeng.2017.12.012

CHANG, S. K.; ALASALVAR, C.; SHAHIDI, F. Review of dried fruits: Phytochemicals, antioxidant efficacies, and health benefits. Journal of Functional Foods, v. 21, p. 113-132, 2016. 10.1016/j.jff.2015.11.034

CHIU, M.; THAM, H.; LEE, J. Osmotic dehydration kinetics of Terung Asam (Solanum lasiocarpum Dunal). International Food
Research Journal, v. 24, n. 6, p. 2365-2370, 2017.

CICHOWSKA, J.; FIGIEL, A.; STASIAK-RÓŻAŃSKA, L.; WITROWA-RAJCHERT, D. Modeling of osmotic dehydration of apples in sugar alcohols and dihydroxyacetone (DHA) Solutions. Foods, v. 8, n. 1, p. 20, 2019. 10.3390/foods8010020

DEHGHANNYA, J.; GORBANI, R.; GHANBARZADEH, B. Effect of ultrasound-assisted osmotic dehydration pretreatment on drying kinetics and effective moisture diffusivity of mirabelle plum. Journal of food processing and preservation, v. 39, n. 6, p. 2710-2717, 2015. 10.1111/jfpp.12521

DEHGHANNYA, J.; HOSSEINLAR, S.-H.; HESHMATI, M. K. Multi-stage continuous and intermittent microwave drying of quince fruit coupled with osmotic dehydration and low temperature hot air drying. Innovative food science and emerging $\begin{array}{lllll}\text { technologies, } & \text { v. } 45, \quad \text { p. } & 132-151, & 2018 .\end{array}$ 10.1016/j.ifset.2017.10.007

DEMIRAY, E.; SEKER, A.; TULEK, Y. Drying kinetics of onion (Allium cepa L.) slices with convective and microwave drying. Heat and Mass Transfer, v. 53, n. 5, p. 1817-1827, 2017. 10.1007/s00231-016-1943-x

FAN, K.; ZHANG, M.; MUJUMDAR, A. S. Recent developments in high efficient freeze-drying of fruits and vegetables assisted by microwave: A review. Critical reviews in food science and nutrition, v. 59, n. 8, p. 1357-1366, 2019. $\underline{10.1080 / 10408398.2017 .1420624}$

FERREIRA, J. P. D. L.; CASTRO, D. S. D.; MOREIRA, I. D. S.; SILVA, W. P. D.; DE FIGUEIRÊDO, R. M.; QUEIROZ, A. J. D. M. Convective drying kinetics of osmotically pretreated papaya cubes. Revista Brasileira de Engenharia Agrícola e Ambiental, v. 24, n. 3, p. 200-208, 2020. 10.1590/18071929/agriambi.v24n3p200-208

GIAMPIERI, F.; TULIPANI, S.; ALVAREZ-SUAREZ, J. M.; QUILES, J. L.; MEZZETTI, B.; BATTINO, M. The strawberry: composition, nutritional quality, and impact on human health. Nutrition, v. 28, n. 1, p. 9-19, 2012. 10.1016/j.nut.2011.08.009

IAL. Normas Análiticas: Métodos químicos e físicos para análise de alimentos: 1020 p. 2008.

ISLAM, M. Z.; DAS, S.; MONALISA, K.; SAYEM, A. S. M. Influence of Osmotic Dehydration on Mass Transfer Kinetics and Quality Retention of Ripe Papaya (Carica papaya L) during Drying. AgriEngineering, v. 1, n. 2, p. 220-234, 2019. $\underline{10.3390 / \text { agriengineering } 1020016}$

KANDASAMY, P.; VARADHARAJU, N.; KALEMULLAH, S.; MALADHI, D. Optimization of process parameters for foammat drying of papaya pulp. Journal of food science and technology, v. 51, n. 10, p. 2526-2534, 2014. 10.1007/s13197012-0812-y

KUCNER, A.; KLEWICKI, R.; SÓJKA, M. The influence of selected osmotic dehydration and pretreatment parameters on dry matter and polyphenol content in highbush blueberry (Vaccinium corymbosum L.) fruits. Food and Bioprocess Technology, v. 6, n. 8, p. 2031-2047, 2013. 10.1007/s11947-012-0997-0 
KUMAR, C.; JOARDDER, M. U. H.; KARIM, A.; MILLAR, G. J.; AMIN, Z. M. Temperature redistribution modelling during intermittent microwave convective heating. Procedia $\begin{array}{lllll}\text { Engineering, } & \text { v. } 90, \quad \text { p. } & \text { 544-549, } 2014 .\end{array}$ 10.1016/j.proeng.2014.11.770

LOPES, F. J.; PEREIRA, N. R.. Encolhimento na secagem convectiva de abacaxi com aplicação de micro-ondas variável. Blucher Chemical Engineering Proceedings, v. 2, n. 1, p. 17071713, 2015.

MENDONÇA, K. S.; CORRÊA, J. L. G.; JESUS JUNQUEIRA, J. R.; PEREIRA, M. C. D. A.; VILELA, M. B. Optimization of osmotic dehydration of yacon slices. Drying Technology, v. 34, n. 4, p. 386-394, 2016. 10.1080/07373937.2015.1054511

MILLER, G. L. Use of dinitrosalicylic acid reagent for determination of reducing sugar. Analytical chemistry, v. 31, n. 3, p. 426-428, 1959. 10.1021/ac60147a030

MUSSATTO, S. I.; ROBERTO, I. C. Xilitol: Edulcorante com efeitos benéficos para a saúde humana. Revista Brasileira de Ciências Farmacêuticas, v. 38, n. 4, p. 401-413, 2002. $\underline{10.1590 / \mathrm{S} 1516-93322002000400003}$

NAJAFI, A. H.; YUSOF, Y.; RAHMAN, R.; GANJLOO, A.; LING, C. N. Effect of osmotic dehydration process using sucrose solution at mild temperature on mass transfer and quality attributes of red pitaya (Hylocereus polyrhizusis). International Food Research Journal, v. 21, n. 2, 2014.

NUNES, A. C. D.; FIGUEIREDO NETO, A.; NASCIMENTO, I. K. S.; DE OLIVEIRA, F. J. V.; MESQUITA, R. V. C. Armazenamento de mamão formosa revestido à base de fécula de mandioca. Revista de Ciências Agrárias, v. 40, n. 1, p. 254263, 2017. 10.19084/RCA16048

PAGE, G. E. Factors influencing the maximum rates of air drying shelled corn in thin layers. West Lafayette: Purdue University, 1949. Thesis Doctoral.

PRATES, R. S. Aspectos operacionais do programa de exportação do mamão brasileiro para os Estados Unidos: sete anos de sucesso. MARTINS, D. Dos S.(Ed.), 2005.

PELEG, M. An empirical model for the description of moisture sorption curves. Journal of Food science, v. 53, n. 4, p. 1216 1217, 1988. 10.1111/j.1365-2621.1988.tb13565.x

RILEY, P.; MOORE, D.; AHMED, F.; SHARIF, M. O., WORTHINGTON, H. V. Xylitol-containing products for preventing dental caries in children and adults. Cochrane Database of Systematic Reviews, n. 3, 2015. 10.1002/14651858.CD010743.pub2

RODRIGUEZ, A.; BRUNO, E.; PAOLA, C.; CAMPAÑONE, L.; MASCHERONI, R. H. Experimental study of dehydration processes of raspberries (Rubus Idaeus) with microwave and solar drying. Food Science and Technology, v. 39, n. 2, p. 336343, 2019. 10.1590/fst.29117

SANTANA, L. R.; MATSUURA, F. C.; CARDOSO, R. L. Genótipos melhorados de mamão (Carica papaya L.): avaliação sensorial e físico-química dos frutos. Food Science and
Technology, v. 24 , n. 2, p. 217-222, 2004. 10.1590/S010120612004000200010

SANTOS, N. C.; BARROS, S. L.; MONTEIRO, S. S.; SILVA, S. N.; RIBEIRO, V. H. A.; SILVA, V. M. A.; GOMES, J. P.; SANTIAGO, A. M.; LUIZ, M. R.; VIEIRA, D.M.; ARAUJO, R. D.; VILAR, S. B. O.; BARROS, E. R. Kinetics of Drying and Physical-Chemical Quality of Peach cv. Hubimel. Journal of Agricultural Science, v. 11, n. 16, p. 223-232, 2019. 10.5539/jas.v11n16p223

SCHWEIGGERT, R.; STEINGASS, C. B.; MORA, E.; ESQUIVEL, P.; CARLE, R. Carotenogenesis and physicochemical characteristics during maturation of red fleshed papaya fruit (Carica papaya L.). Food Research International, v. 44, n. 5, p. 1373-1380, 2011. 10.1016/j.foodres.2011.01.029

SHARMA, G. P.; PRASAD, S. Effective moisture diffusivity of garlic cloves undergoing microwave-convective drying. Journal of Food engineering, v. 65, n. 4, p. 609-617, 2004. 10.1016/j.jfoodeng.2004.02.027

SILVA, F. D. A. E.; AZEVEDO, C. D. The Assistat Software Version 7.7 and its use in the analysis of experimental data. African Journal of Agricultural Research, v. 11, n. 39, p. 37333740, 2016.

STATSOFT. Statistica 7.0 Software. StatSoft, Inc Tucksa, 2004.

STROHECKER, R.; HENNING, H. M. Análise de vitaminas: métodos comprovados. Madrid: Paz Montalvo, 1967. 428p.

SULISTYAWATI, I.; VERKERK, R.; FOGLIANO, V.; DEKKER, M. Modelling the kinetics of osmotic dehydration of mango: Optimizing process conditions and pre-treatment for health aspects. Journal of Food Engineering, p. 109985, 2020. 10.1016/j.jfoodeng.2020.109985

UDOMKUN, P.; NAGLE, M.; MAHAYOTHEE, B.; NOHR, D.; KOZA, A.; MULLER, J. Influence of air drying properties on non-enzymatic browning, major bio-active compounds and antioxidant capacity of osmotically pretreated papaya. Food Science and Technology, v. 60, n. 2, p. 914-922, 2015. $\underline{10.1016 / j .1 w t .2014 .10 .036}$

VEGA-GÁLVEZ, A.; POBLETE, J.; QUISPE-FUENTES, I.; URIBE, E.; BILBAO-SAINZ, C.; PASTÉN, A. Chemical and bioactive characterization of papaya (Vasconcellea pubescens) under different drying technologies: evaluation of antioxidant and antidiabetic potential. Journal of Food Measurement and Characterization, v. 13, n. 3, p. 1980-1990, 2019. $\underline{10.1007 / s 11694-019-00117-4}$

WEIBULL, W. Wide applicability. Journal of applied mechanics, v. 103, n. 730, p. 293-297, 1951.

ZERPA-CATANHO, D.; ESQUIVEL, P.; MORANEWCOMER, E.; SÁENZ, M. V.; HERRERA, R.; JIMÉNEZ, V. M. Transcription analysis of softening-related genes during postharvest of papaya fruit (Carica papaya L.'Pococí'hybrid). Postharvest biology and technology, v. 125, p. 42-51, 2017. 10.1016/j.postharvbio.2016.11.002 